\title{
Antimicrobial profile of essential oils extracted from wild versus cultivated Origanum ehrenberjii against enteric bacteria
}

\author{
Elie K Barbour ${ }^{1,2}$, Samar K Dankar ${ }^{1}$, Houssam A Shaib ${ }^{1}$, Taha Kumosani ${ }^{2}$, Esam Azhar ${ }^{3,4}$, Saad \\ Masaudi $^{5}$, Archana lyer ${ }^{2}$, Steve Harakeh ${ }^{3}$ \\ ${ }^{1}$ Department of Animal and Veterinary Sciences, Faculty of Agricultural and Food Sciences (FAFS), American \\ University of Beirut (AUB), P.O. Box 11-0236, Beirut, Lebanon \\ ${ }^{2}$ Biochemistry Department, King Abdulaziz University, Jeddah, Saudi Arabia \\ ${ }^{3}$ Special Infectious Agents Unit - Biosafety Level 3, King Fahd Medical Research Center; King Abdulaziz \\ University, Jeddah, Saudi Arabia \\ ${ }^{4}$ Medical Laboratory Technology Department, Faculty of Applied MedicalSciences, King Fahd Medical Research \\ Center, King Abdulaziz University, Jeddah, Saudi Arabia \\ ${ }^{5}$ Biology Department, King Abdulaziz University, Jeddah, Saudi Arabia
}

\begin{abstract}
Introduction: The role of Origanum ehrenberjii against bacteria that cause enteric diseases is well known. Salmonella and Enterococcus cause high rates of enteric infections around the world. The aim of this study was to extract essential oils from cultivated and naturally growing $O$. ehrenberjii, compare the chemical profiles of the extracts and estimate their antimicrobial efficacy against enteric pathogens.

Methodology: Sixteen compounds were recovered consistently from essential oils extracted from O. ehrenberjii of wild and cultivated origin. The chemical profiles were determined using GC-MS. Safety of the essential oils was determined by observing mortality of chicks after intramuscular administration of the oils. The antimicrobial efficacy of the oils against the enteric pathogens was determined by the KirbyBauer Single Disk Diffusion assay.

Results: The levels of thymol, carvacrol, para cymene and $\gamma$-terpinene were significantly different in the two oils. A significant difference in in vitro antimicrobial activity of the two oils against Salmonella enterica serovar Typhimurium was observed. Intramuscular administration of the two oils in one day-old chicks resulted in significant differences in mortality of $60 \% \mathrm{vs} .5 \%(\mathrm{p}<0.05)$ for wild and cultivated herbs respectively, reflecting the higher safety of the cultivated herb due to the differences in the levels of certain active ingredients.

Conclusions: The chemical profile of essential oil of wild vs. cultivated $O$. ehrenberjii differ significantly at compound level, suggesting the reason for their significant difference in efficacy against Salmonella enterica serovar Typhimurium, and also significant differences in the toxicity of the two oils.
\end{abstract}

Key words: Antimicrobials; Carvacrol; Enterococcus feacalis; para Cymene safety; Salmonella Typhyimurium; $\gamma$-Terpinene, Thymol.

J Infect Dev Ctries 2014; 8(10):1344-1349. doi:10.3855/jidc.4774

(Received 27 January 2014 - Accepted 18 Septembre 2014)

Copyright (c) 2014 Barbour et al. This is an open-access article distributed under the Creative Commons Attribution License, which permits unrestricted use, distribution, and reproduction in any medium, provided the original work is properly cited.

\section{Introduction}

Origanum ehrenberjii is originally an endogenous herb of Lebanon, used as a decoction in folk medicine to clear enteric infections. Common side effects associated with usage include fatigue, irritation of the intestine and severe dizziness [1-3]. Attempts at cultivation of this herb were successful at the Agricultural Research and Education Center (AREC), a Research unit of the American University of Beirut located at an altitude of $1,000 \mathrm{~m}$ above sea level, and North at $34^{\circ} 54^{\prime}$ latitude and East at $36^{\circ} 45^{\prime}$ 'Meridian.

Enteric pathogens such as Enterococous faecalis cause high rate of infection in humans whereas
Salmonella enterica serovar Typhimurium infects both humans and animals [4-7]. The wide prevalence of resistance in these organisms to conventional antibiotics [8-11] has resulted in efforts to find alternative holistic approaches to reduce such infections in humans $[12,13]$ and in animal serving as vectors for zoonoses affecting humans [14].

The objective of this work was to extract essential oils from $O$. ehrenberjii of wild and cultivated origin and compare their chemical profile and in vitro efficacy against Salmonella enterica serovar Typhimurium and E. faecalis. The toxicity of the oils were also evaluated in one-day-old chick model, a 
vector in zoonoses; against the established toxicity of amantadine sulfate used commercially against the influenza virus, which causes common infections between avians and humans.

\section{Methodology}

Essential oil source and preparation

Two batches of essential oil were extracted by steam distillation from two separate harvests of each of the wild and cultivated Origanum ehrenberjii. The wild and cultivated plants were cut at $10 \mathrm{~cm}$ above the ground, dried at room temperature for 10 days, and kept for 4 hours before distillation. The procedure of steam distillation was carried out as previously, described [15].

\section{Chemical profiles of extracted essential oils}

The chemical profiles of the two batches of extracted oils from the wild vs. the two batches from the cultivated $O$. ehrenberjii were determined by a previously described procedure of GC-MS [16].

\section{Safety study of the essential oils}

This project included 80-day-old male chicks that were humanely treated according to the approved document presented by the Animal Care and Use Committee (IACUC) at the American University of Beirut. The termination of the study took place at 48 hours post administration of the substances by humanely euthanizing the birds by $\mathrm{CO}_{2}$ according to the IACUC set recommendations. The chicks were divided into four different groups and received the following treatments: each chick of the first group was administered intramuscularly (pectoral muscle) with $50 \mu 1$ of 1:600 dilution in 40\% DMSO of the essential oils from wild $O$. ehrenberjii. The same treatment was applied to all birds in the second group using the essential oil from cultivated $O$. ehrenberjii. Each bird from the third group was administered intramuscularly (pectoral muscle) with $50 \mu 1$ of amantadine sulfate (PK-Merz, Pharma, Frankfurt, Germany), a reference anti-influenza commercialized drug, with an equivalence of $1 \mathrm{mg} / \mathrm{ml} \mathrm{blood,} \mathrm{according} \mathrm{to} \mathrm{the}$ manufacturer instructions. The amantadine sulfate was widely used against avian influenza viruses. However, the emergence of resistance of the influenza viruses to this drug has become very evident [17]. For this reason, alternative treatments have been sought. Some of those possible alternatives include the use of holistic approaches based on the utilization of essential oils for the treatment of resistant influenza infections. The fourth group was not given any treatment and served as the control. The cumulative percentage mortality was determined in each group, following the treatments at 24 and 48 hours.

In vitro efficacy of essential oils against enteric bacteria

In vitro efficacy of the two batches of essential oils from wild and cultivated $O$. ehrenberjii against two enteric bacteria namely, Salmonella enterica serovar Typhimurium (Gram negative) and E. faecalis (Gram positive), was determined by Kirby-Bauer Single Disk Diffusion assay. The two bacteria were provided by Dr. George Araj, head of the Microbiology Laboratory at the American University of Beirut Medical Center (AUB-MC), Beirut, Lebanon. Briefly, each of the essential oil batches was subjected to a serial dilution with a dilution factor of $1 / 2$ ranging from $1: 100$ to 1:900 in sterile $40 \%$ DMSO. Blank discs were loaded with $20 \mu \mathrm{l}$ of $40 \%$ DMSO resulting in absence of growth inhibition of both bacteria used in this experimental design. The bacterial density was adjusted to the second tube of the MacFarland series, to around $10^{9} \mathrm{cfu} / \mathrm{ml}$, before plating $0.1 \mathrm{ml}$ of the bacterial suspension on Muller-Hinton agar plates (Mast Group Ltd., Merseyside, UK). The volume of each essential oil dilution applied to the sterile blank disc was $20 \mu 1$. The blank disc was $6.5 \mathrm{~mm}$ in diameter. The agar plates were incubated at $37^{\circ} \mathrm{C}$ for 24 hours.

\section{Statistics}

The statistical differences in the average percentage of each compound present in chemical profile of wild versus cultivated batches of $O$. ehrenberjii was determined by one-way ANOVA followed by Tukey's Test. Significant differences were reported at $p<0.05$. The same statistical method was used to compare the average ratio of the percentages of Carvacrol/Thymol in the wild vs. cultivated batches of $O$. ehrenberjii, and also to compare the average diameter of bacterial growth inhibition in the agar plates.

\section{Results}

The consistent chemical profile of the 16 components extracted from different batches of either the wild or the cultivated $O$. ehrenberjii is shown in Table 1. 
Table 1. Comparison of the chemical profile of essential oil components extracted from different batches of wild versus cultivated O.ehrenbergii

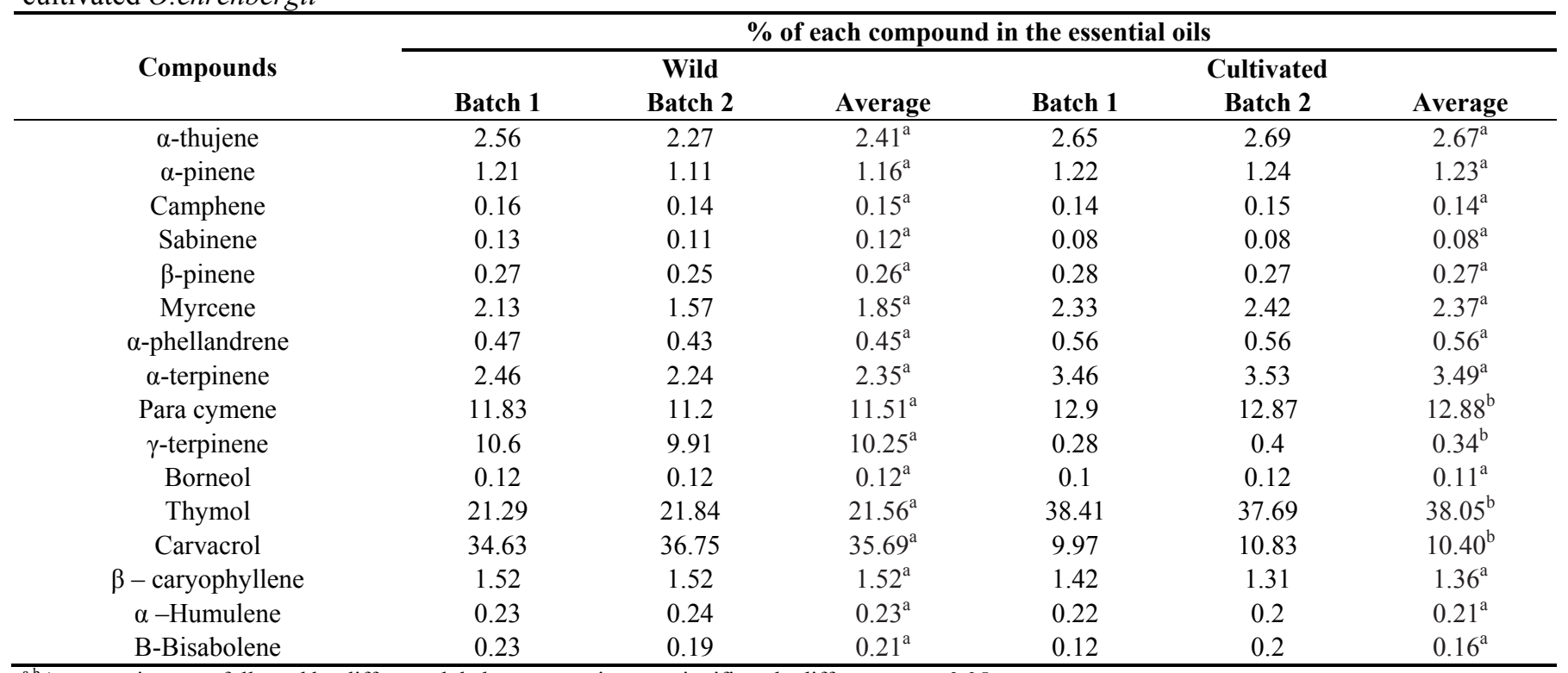

${ }^{\mathrm{a}, \mathrm{b}}$ Averages in a row followed by different alphabet superscripts are significantly different at $\mathrm{p}<0.05$

Table 2. Comparison of the safety of essential oils of wild versus cultivated O.ehrenberjii in day-old chicken model ${ }^{1}$

\begin{tabular}{|c|c|c|c|}
\hline \multirow{2}{*}{ Treatment } & \multirow{2}{*}{ Source } & \multicolumn{2}{|c|}{ Cumulative \% mortality at 24 and 48 hours following treatment ${ }^{2}$} \\
\hline & & 24 hours & 48 hours \\
\hline Essential oil, O.ehrenberjii & Wild & $25.0^{\mathrm{a}}$ & $60.0^{\mathrm{a}}$ \\
\hline Essential oil, O. ehrenberjii & Cultivated & $0.0^{\mathrm{b}}$ & $5.0^{\mathrm{b}}$ \\
\hline Control $^{4}$ & - & $0.0^{\mathrm{b}}$ & $0.0^{\mathrm{b}}$ \\
\hline
\end{tabular}

${ }^{1}$ The essential oils and amantidine sulfate were administered intramuscularly in the pectoral muscle; ${ }^{2}$ Cumulative $\%$ mortality in each group was recorded following the different treatments by 24 and 48 hours; ${ }^{3}$ Amantadine sulfate (PK-Merz,Pharma, Frankfurt, Germany); ${ }^{4}$ Control group was deprived of treatment; ${ }^{\mathrm{a}-\mathrm{b}}$ Cumulative $\%$ mortality in a column, followed by different alphabet superscripts, are significantly different $(\mathrm{p}<0.05)$.

Figure 1. Average percentage of Carvacrol and Thymol in two batches of extracted essential oils of two harvests of each of Wild (W) versus another two harvests of Cultivated (C) Origanum ehrenberjii. The presence of different alphabet letters over the histogram representing the average $\%$ of a substance in essential oil of the Wild vs. Cultivated $O$. ehrenberjii is indicative of a significant difference in the compared averages at $\mathrm{p}<0.05$.

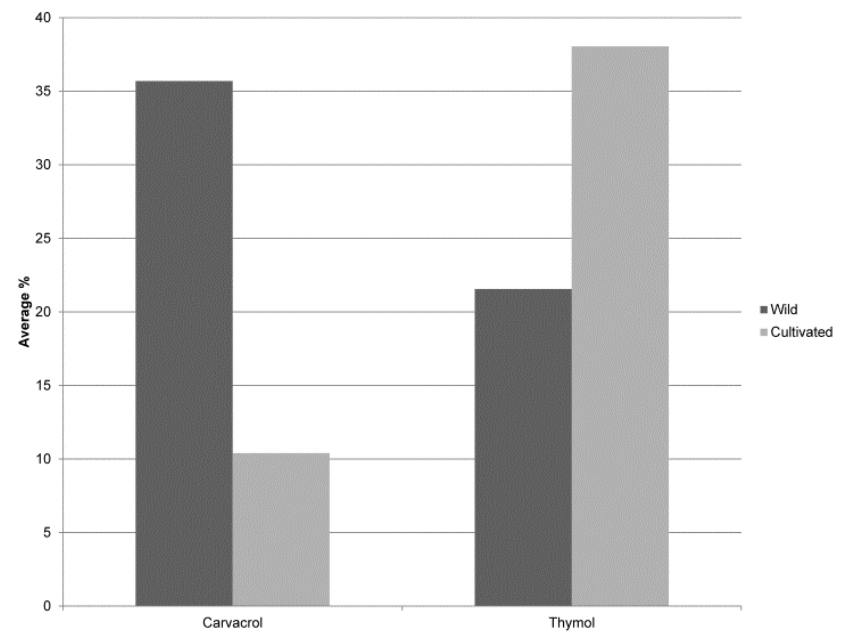

Figure 2. Average diameter of inhibition (mm) resulting from different dilutions of essential oils (1:100-1:900) applied in the Single Diffusion Assay against $S$. typhimurium and E. faecalis. Different alphabet letters shown at the top of this histogram indicates a statistical difference in the antimicrobial efficacy of essential oils of wild vs. cultivated $O$. ehrenberjii $(\mathrm{p}<0.05)$. The presence of different alphabet over the histogram representing the average diameter of inhibition by different dilutions of essential oil indicates a statistical difference in efficacy of these dilutions against a specific Enteric test organism at $\mathrm{p}<0.05$.

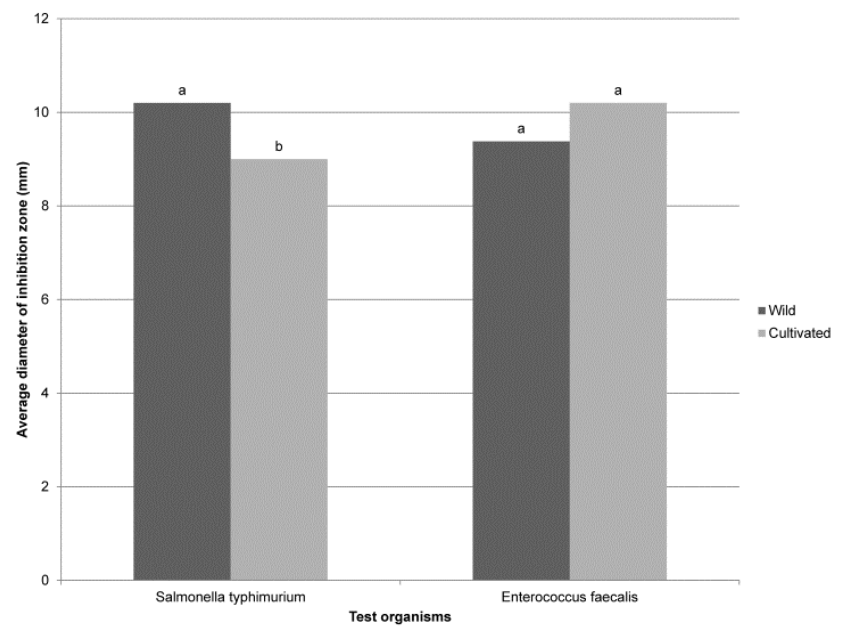


The averages of the majority of compounds (12) quantified in different batches of wild versus cultivated $O$. ehrenberjii were insignificantly different $(p>0.05)($ Table 1); however, the percentage of only four compounds differed significantly in the essential oils of the wild versus the cultivated herb namely thymol $(21.56 \%$ vs. $38.05 \%$, respectively) $(\mathrm{p}<0.05)$, carvacrol (35.69 vs. $10.40 \%)(\mathrm{p}<0.05)$, para cymene $(11.51$ vs. 12.88$)(\mathrm{p}<0.05)$ and $\gamma$-terpinene $(10.25$ vs. $0.34)(\mathrm{P}<0.05)$ (Table 1 and Figure 1). This resulted in Carvacrol \% to Thymol \% ratio of 1.6 to 0.27 in essential oils of the wild vs. cultivated herb $(p<0.05)$.

Results of the in vitro susceptibility of different dilutions (1:100 - 1:900) of the essential oils of wild or cultivated herb against Salmonella enterica serovar Typhimurium and E. faecalis are shown in Figure 2. There were significant differences in the in vitro antimicrobial activity of the essential oils against Salmonella enterica serovar Typhimurium ( $\mathrm{p}<0.05)$, with the wild herb essential oil showing a superior efficacy. In addition, the essential oils from both sources were of comparable efficacy against $E$. faecalis $(\mathrm{p}>0.05)$ (Figure 2), in spite of the higher Carvacrol and $\gamma$-Terpinene levels in the essential oil of the wild compared to that of the cultivated herb.

The data pertaining to the evaluation of the safety of essential oils derived from either the wild or the cultivated herb was carried out using a one-day-old chick as a model (Table 2). Amantadine sulfate, used to treat influenza viral infections, was included in the safety study as a reference control since the compound had been evaluated to be safe for commercialization. This allows the comparison of the percent mortality obtained using one-day-old chicks administered either one of the two oils versus those on amantadine sulfate which is a licensed-safe drug and to the control chicks that were deprived of any oil or medication. Amantadine sulfate is known for its low toxicity to cellular systems and to living organisms, with very minimal side effects $[18,19]$.

The essential oil of the wild herb proved highly toxic, killing $25 \%$ and $60 \%$ of the chicks 24 and 48 hours after the administration, respectively. However, the essential oil of the cultivated herb was significantly less toxic, killing $0 \%$ and $5 \%$ of the chicks 24 and 48 hours after the administration, respectively $(p<0.05)$. The two reference groups, namely amantadine sulfate and the untreated control group, had $100 \%$ survivors after 24 and 48 hours.

\section{Discussion}

This study represents the first documentation on the variation of components of $O$. ehrenberjii harvested from the wild vs. cultivated crop. The significant difference in the level of expression of the four active ingredients in wild vs. cultivated $O$. ehrenberjii is most likely due to environmental factors. A literature search on earlier publications suggests a dearth of research investigating the effect of the environment on the level of expression of different components in essential oils of Origanum species $[20,21]$. One citation pointed at the effect of water stress on plant growth and Thymol and Carvacrol concentrations in the Mexican Oregano grown under controlled conditions [20,21]. To our knowledge, no citations exists documenting the impact of other environmental conditions on the level of expression of the four compounds in the essential oil of $O$. ehrenberjii.

The presence of a higher percentage of Carvacrol in the essential oil of the wild vs. the cultivated herb could be the reason for its superior antimicrobial activity against Salmonella enterica serovar Typhimurium. Previous work by Verder-Unlu et al, (2007) confirmed that the anti-Salmonella enterica serovar Typhimurium activity shown in the essential oil of O. minutiflorum, endemic species in Turkey, was mainly due to Carvacrol which forms a major component in that oil $(793.4 \mathrm{ml} / \mathrm{l})$. The essential oil of this endemic Turkish species of Origanum was previously shown to be effective in an in vitro study against Salmonella enterica serovar Typhimurium [22]. The oil of other Origanum species (O. vulgare) have also been shown to have high anti-Salmonella activity $[23,24]$.

The antimicrobial activity of the essential oils against both Gram-positive and Gram-negative bacteria in spite of the difference in their cell wall structure $[25,26]$ suggests that these oils target other biochemical pathways in the bacteria. It is worth noting that the essential oils of other species of Origanum showed an anti-E. Faecalis activity [16]. To our knowledge, there is no previous study in literature documenting the antimicrobial activity of $O$. ehrenberjii against Salmonella enterica serovar Typhimurium and E. faecalis, or any other related test organisms.

The toxicity of the wild as compared to the cultivated herb is most likely due to the impact of the difference in carvacrol/thymol ratios in essential oils of wild vs. cultivated herb (1.6 vs. 0.27 , respectively) and possibly due to differences in the levels of the para 
cymene and $\gamma$-terpinene. Earlier studies have shown that carvacrol and thymol induce toxicity in mammalian cells [27,28]. Another study showed a significant effect of carvacrol on sister chromatid exchanges in human lymphocyte cultures [29,30]. The genotoxicity of carvacrol has also been evaluated using the Ames Salmonella/microsome test [31,32]. These indications of toxicity by carvacrol and thymol were later shown to be due to the activity of thymol on sister chromatid leading to chromosome aberration and micronucleus in human lymphocytes even at very low drug concentrations.

In conclusion, the chemical profile of essential oil of wild vs. cultivated $O$. ehrenberjii differ significantly in the levels of four compounds which could be the reason for their significant difference in efficacy against Salmonella enterica serovar Typhimurium, and in significant differences in the toxicity of the two oils on baby chicks.

\section{Acknowledgments}

The authors like to express their gratitude to Dr. Najat Saliba, Department of Chemistry, Faculty of Arts and Sciences, American University of Beirut for conducting the chemical analyses of the essential oils.

\section{References}

1. Kim HD, Lee SK, Chun BG, Lee DH, Jang BK, Korean J (1994) Illness associated with contamination of drinking water supplies with phenol. J Korean Med Sci 9: 218-223.

2. Ibrahim L, Karaky M, Ayoub P, El Ajouz N, Ibrahim S (2012) Chemical composition and antimicrobial activities of essential oil and its components from Lebanese Origanum syriacum L. J Essent Oil Res 24: 339-345.

3. Nguyen H, Kim SM (2012) Antioxidative, anticholinesterase and antityrosinase activities of the red alga Grateloupia lancifolia extracts. Afr J.Biotechnol 11: 9457-9467.

4. Poppe C., Smart N, Khakhria R, Johnson W, Spika J, Prescott J (1998) Salmonella typhimurium DT104: a virulent and drugresistant pathogen. Can Vet J 39: 559-565.

5. Murray B. (2000). Vancomycin-Resistant Enterococcal Infections. N Engl J Med 342: 710-721.

6. Arda S, Ergin F, Varan B, Demirhan B, Aslan H, Zyaylali P (2001) Acute abdomen caused by Salmonella typhimurium infection in children. J Pediatr Surg 36: $1849-1852$.

7. Ailes E, Budge P, Shankar M, Collier S, Brinton W, Cronquist A, Chen M, Thornton A, Beach MJ, Brunkard JM (2013) Economic and health impacts associated with a Salmonella Typhimurium drinking water outbreak- Alamosa, CO, 2008." PloS one 8.3: e57439.

8. Huycke MM, Sahm DF, Gilmore MS (1998) Multiple-drug resistant enterococci: the nature of the problem and an agenda for the future. Emerging Infect Dis 4: 239-249.

9. Onyango D, Machoni F, Kakai R, Waindi EN. (2008). Multidrug resistance of Salmonella enterica serovars Typhi and Typhimurium isolated from clinical samples at two rural hospitals in Western Kenya. J Infect Dev Ctries 2: 106 - 111. doi:10.3855/jidc. 279 .

10. Park S, Song SH, Lee C, Kim JW, Kim KS (2013) Bacterial Pathogens in First Febrile Urinary Tract Infection Affect Breakthrough Infections in Infants With Vesicoureteral Reflux Treated With Prophylactic Antibiotics. Urology 81: 1342-1345.

11. Johnson L, Horsman SR, Charron-Mazenod L, Turnbull AL, Mulcahy H, Surette MG, Lewenza S (2013) Extracellular DNA-induced antimicrobial peptide resistance in Salmonella enterica serovar Typhimurium. BMC microbiol. 13: 115.

12. Van Vuuren SF, Viljoen AM. (2008). In vitro evidence of phyto-synergy for plant part combinations of Croton gratissimus (Euphorbiaceae) used in African traditional healing. J Ethnopharmacol 119: 700-704.

13. Nowack R, Schmitt W (2008) Cranberry juice for prophylaxis of urinary tract infections - Conclusions from clinical experience and research. Phytomedicine 15: 653-667.

14. Kwon HA, Kwon YJ, Kwon DY, Lee JH (2008) Evaluation of antibacterial effects of a combination of Coptidis Rhizoma, Mume Fructus, and Schizandrae Fructus against Salmonella. Int J Food Microbiol 127: 180-183.

15. Chialva, F, Gabri G, Liddle PAP, Ulian F (1982) Qualitative evaluation of aromatic herbs by direct head space (GC)2 analysis. Applications of the method and comparison with the traditional analysis of essential oils. In: N. Margaris, A. Koedam, and D. Vokou (eds.). Aromatic plants-basic and applied aspect. Martinus Nijhoff Publishers, Dordrecht, The Netherlands. 183-195.

16. Bouhdid S, Skali SN, Idaomar M, Zhiri A, Baudoux D, Amensour M, Abrini J (2008) Antibacterial and antioxidant activities of Origanum compactum essential oil. Afr J Biotechnol 7 : 1563-1570.

17. Monto, AS (2003) Use of selective viral cultures to adjust nonvirologic endpoints in studies of influenza vaccine efficacy. Amer J Epidemiol 158: 312-315.

18. Boreko EI, Pavlova NI, Votyakov VI (1996) Antiviral effectsof carbocyclic compounds in different concentrations. Vopr Virusol 3: 129-133.

19. Staničová J, Kovalčík L, Chinsky L, Miškovský P (2001) Preresonance Raman and surface-enhanced Raman spectroscopy study of the complex of the antiviral and antiparkinsonian drug amantadine with histidine. Vib Spectrosc 25: 41-51.

20. Vazquez SR, Dunford NT (2005) Bioactive components of Mexican Oregano oil as affected by moisture and plant growth. J Essent Oil Res 17: 668-671.

21. Avila-Sosa R, Gastélum-Reynoso G, García-Juárez M, de la Cruz Meneses-Sánchez M, Navarro-Cruz AR, DávilaMárquez RM (2011) Evaluation of Different Mexican Plant Extracts to Control Anthracnose. Food Bioprocess Tech 4: 655-659.

22. Dadalioglu I, Evrendilek GA (2004) Chemical compositions and antibacterial effects of essential oils of Turkish Oregano (Origanum minutiflorum), Bay Laurel (Laurus nobilis), Spanish Lavender (Lavandula stoechas L.), and Fennel (Foeniculum vulgare) on common foodborne pathogens. J Agricult Food Chem 52: 8255-8260

23. Chaudhry NMA, Saeed S, Tariq P (2007) Antibacterial effect of Oregano (Origanum vulgare) against gram negative bacilli. Pak J Bot 39: 609- 613.

24. da Silva Luz I, Neto NJG, Tavares AG, Nunes PC, Magnani M, de Souza EL (2012). Evidence for lack of acquisition of tolerance in Salmonella enterica serovar Typhimurium ATCC 
14028 after exposure to subinhibitory amounts of Origanum vulgare L. essential oil and carvacrol. Appl Environ Microbiol 78: 5021-5024.

25. Walsh C (2003) Antibiotics: Actions, Origins, Resistance. Washington, D.C.: American Society for Microbiology Press, $335 \mathrm{pp}$.

26. Xiong $\mathrm{X}$, Bromley $\mathrm{EH}$, Oelschlaeger $\mathrm{P}$, Woolfson DN, Spencer J (2011) Structural insights into quinolone antibiotic resistance mediated by pentapeptide repeat proteins: conserved surface loops direct the activity of a Qnr protein from a Gram-negative bacterium. Nucleic acids Res 39: 39173927.

27. Azirak S, Rencuzogullari E (2008) The in vivo genotoxic effects of carvacrol and thymol in rat bone marrow cells. Environ Toxicol 23: 728-735.

28. Kim SI, Ahn YJ, Kwon HW (2012) Toxicity of Aromatic Plants and Their Constituents Against Coleopteran Stored Products Insect Pests. New perspectives in plant protection, Ali R. Bandani (Ed.), ISBN: 978-953-51-0490-2, InTech, DOI: $\quad 10.5772 / 36288$. Available at: http://www.intechopen.com/books/new-perspectives-in-plantprotection/toxicity-of-aromatic-plants-and-their-constituentsagainst-coleopteran-stored-products-insect-pests. Last accessed on July 15, 2013.

29. Ipek E, Tuylu BA, Zeytinoglu H (2003) Effects of carvacrol on sister chromatid exchanges in human lymphocyte cultures. Cytotechnology. 43: 145- 148.
30. Kocaman AY, Rencüzoğulları E, Topaktaş M, İstifli ES, Büyükleyla M (2011) The effects of 4-thujanol on chromosome aberrations, sister chromatid exchanges and micronucleus in human peripheral blood lymphocytes. Cytotechnology 63: 493-502.

31. Ipek E, Zeytinoglu H, Okay S, Tuylu BA, Kurkcuoglu M, Baser KHC (2005) Genotoxicity and antigenotoxicity of origanum oil and carvacrol evaluated by Ames Salmonella/microsomal test. Food Chem 93: 551-556.

32. Ceker S, Nardemir G, Alpsoy L, Agar G, Mete E (2012) AntiGenotoxic and Anti-Oxidant Effects of Origanum rotundifolium on Human Lymphocytes In vitro. J. Essent. Oil Bear Pl 15: 415-423.

\section{Corresponding author}

\section{Steve Harakeh,}

Special Infectious Agents Unit - Biosafety Level 3, King Fahd

Medical Research Center;

King Abdulaziz University, Jeddah, Saudi Arabia.

Phone: +966559392266

Fax: +96626952076

Email: sharakeh@gmail.com

Conflict of interests: No conflict of interests is declared. 